\title{
Research on the Marketing System of Electric Power Company under the Electric Power System Reform
}

\author{
Yun-yan Li, Yuan-sheng Huang, Juan Chen \\ Department of Economic Management, North China Electric Power University, Baoding, China
}

Keywords: Electricity market reform, Sale enterprise, Marketing system

\begin{abstract}
Some opinions on further deepening the reform of electric power system,9 text, once again open the national electricity reform curtain, which is the biggest selling electricity market liberalization highlights. Release the sale of electricity, will break the monopoly of the Power Grid Corp purchase and sale of electricity production and the relationship between enterprises and users of long-term isolation of power sale market marketing brings new changes. Based on the analysis of power sale market after the new electricity reform, research on the company's sale of electricity marketing system, based on the analysis of factors of the sales price, service level so, to determine the degree of influence on customer choice, and puts forward some suggestions.
\end{abstract}

\section{Introduction}

Research Background. A new round of electricity reform to further promote the sale of the end of the market process, the power system is both a challenge and an opportunity for the sale of electricity side to allow the participation of a variety of sales of electricity, the construction of the market system to introduce competition [1]. In addition to selling electricity company of Power Grid Corp, a single large, power enterprises will face the end of the sale of electricity saving service based on distributed power, park, set up the sale of electricity company's social capital competition, at the same time because the electric power enterprises has long focused on the field of power generation, more sales for the national network of single large customers, although there has been to carry out the direct purchase of large users, but more is under the guidance of the government, power companies unilateral price none other consumers Affected by the traditional mode of power market sales in the market competition in the marketing concept, marketing organization and marketing strategy [2]. Customer service level is insufficient, because the power of homogeneous products, customers choose to consider the electricity supplier is more price and service, need to continue active improvement walking in the forefront of reform, the establishment of the sale of electricity sales system.

Impact of Opportunities and Challenges. The environment of power market open, the sale of electricity companies lose the regional monopoly position, facing a number of retail companies compete for market share. The sale of electricity companies to provide electricity sales service contract type, contract rate plays a decisive role in the allocation of market share in the direct influence of retail companies revenue and resist the market risk, thus increasing market share, expand their revenue has become one of the key problems of electric sale company, in addition to the price is also influenced by the factors of service quality [3-4].

\section{Methods and Materials}

When there are a number of competing individuals in the market, whether the user selects a certain sales company depends on the attractiveness of the company to the user [5].

With probability $\mathrm{P}$ indicates that the sale of electricity companies attractive for users, users will be based on the probability distribution of their purchasing power, the probability depends on the attractiveness of the sale of electricity company, and the sales price, service level is closely related to a number of factors, can use "utility" to reflect the sale of electricity companies, also on behalf of a decision the choice of different retail companies for their own benefit, decision makers always selected for their highest utility program, the user utility function determines the sale of electricity 
companies to occupy market share [6]. Therefore, we need to determine the utility psychological activity was quantified. With the opening of the market competition, the user has the right to freedom of choice of power, because the sale of electricity sales of electricity from power suppliers, there is strong competition and substitution between the sales of electricity companies. According to the traditional marketing research contents and conclusions of this paper, influence of user power key factors of power suppliers selection deconstruction and analysis.

Table 1 hierarchy model of user utility

\begin{tabular}{ccc}
\hline utility & Criterion layer & Index layer \\
\hline User utility & Price competition & Electricity price \\
& Brand competition & $\begin{array}{c}\text { Corporate image } \\
\text { service level } \\
\text { Regional scale } \\
\end{array}$ \\
& Composition of contract \\
\hline
\end{tabular}

Price Competition. Electric energy prices, is the most important factor in the sale of the company's market share, but also a direct impact on the final profit of the sale of the company, the sale of the company's competition will eventually be reflected in the price strategy.In the modern information society more and more developed, consumers become more rational, therefore, the sale of electricity companies must formulate an effective and reasonable price strategy to provide the competitive power of service price for the user, can be in an invincible position in a rapidly changing marketPrice competition as a marketing tool is an important means to seize market share in the market.In the process of marketing, enterprises in order to achieve the strategic blueprint and their business objectives, often need according to the market demand and the level of competition, adjust its pricing strategy, the sales price can better adapt to market development, to promote the enterprises to expand sales, to obtain higher returns.

When the sale price is fixed, the sale price is determined according to the market strategy, considering to the business model and sales model of the product, and make the corresponding price strategy according to the strategic intention matrix.

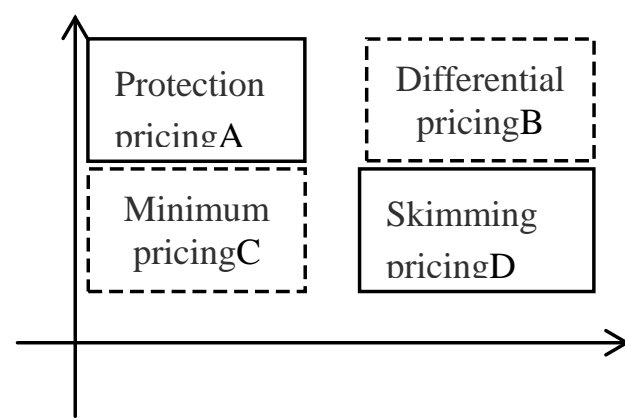

Figure 1 strategic intent matrix

According to the difference of product price and market share, the strategic positioning of the company's products can be divided into four categories:

(1)Protection pricing area A: Price is set to maintain a strong market share to attract prices;

(2)Differential pricing area B: Realize the difference, in this region, high prices will not affect the market share of access;

(3) M inimum pricing area C: Price is set to ensure that the market share of the price setting;

(4)High pricing area D: In this region, the emphasis is on the short-term high profits.

In the retail electricity market competitive power, because the products are from the wholesale market, the retail companies to provide electricity products had no obvious difference in quality. According to the different market positioning of the company's sale of electricity, in order to compete for market share as the goal, the sale of electricity companies will adopt low-cost marketing strategies in area A; with the maximum benefit as the goal, the sale of electricity companies will be comprehensive sales price and market share, maintain a high price level, fall in 
area D.

In the competitive market environment, the sale of electricity companies not only need to cost oriented, but also need to be combined with the market environment and the company's strategic intent to price, and according to market segments to further differences in pricing.

Brand Competitiveness. Brand is the consumer for the visual impression of the enterprise, corporate image and reputation, is the embodiment of the core value, is the power users continue to choose the products or services. For users, the sale of electricity company brand means power supply stability, excellent after-sales service and more cost-effective. This paper summarizes the main factors that affect the brand image.

(1)Corporate image and word of mouth: Corporate image and reputation from the sale of electricity companies to provide power supply and after-sales service quality, is a key factor in the sale of the company has a good brand image.

(2)Regional scale: Regional scale to a certain extent, represents the power of the sale of electricity companies and the ability to resist risks, in general, the larger the scale, the higher the degree of trust the user to the company, the higher the brand value of the sale of electricity.

(3)Contract structure: In the sale of electricity side open market situation, the sale of electricity companies to provide electricity sales contract towards freedom, the direction of diversification, the sale of electricity contract structure is reasonable, the sales price is reasonable, whether the value of money in the eyes of users, has become an important factor affecting the value of the brand.

According to their own use of electricity, in the choice of the right of the sale of the company, the importance of considering the impact of the various factors.

\section{Marketing By Category}

Market segmentation is aimed at different target markets, to take different marketing strategies to achieve effective market sales, in line with the characteristics of the market.

Target Market Efficiency. Benefit target market is a collection of users who have the main benefit of local electricity in the whole power users, mainly divided into: the residents live with electricity, commercial electricity, industry power.

Structural Target Market. Structure target market refers to the user in the entire electricity market, not as long as the profit direction.For example: nonresident life with electricity, agricultural production of electricity.

The Target Market for Public Welfare. Public object market refers to a small number of users in the power users in the collection of this kind of user can not only bring the profit for the power company, and its price is low will cut power company profits, the user power is very low, but can help the power company to establish a public service image of power supply enterprises.According to the above analysis, this type of users are mainly: Agricultural row of electricity, lighting electricity, the country belongs to the social welfare institutions

The role of market segmentation is to effectively select and enter the target market. As the power products, we do not choose whether to enter some markets, but for different target markets, we can adopt different marketing strategies and tactics.

\section{Conclusions}

(1) A sound marketing system is established. At present, China's power enterprises due to long-term wholesale to marketing system is weak, power enterprises should set up market sales department. The door, perfect the marketing process system, personnel structure, platform construction, security system, clear division headquarters, branch, subsidiary and grass-roots power plant duty. Along with the electric power futures market in our country, and gradually establish a carbon trading market, the group companies can set up a specialized two trading company, the group responsible for the wholesale power market and the electric power futures and other financial derivatives trading.

(2)The focus of the retail market is based on the integration of the holding or shares based on the park. Because of the power of homogeneous products, customers choose to consider the electricity 
supplier is more price and services. Through its own power allocation, power consumption organization resources external procurement, and the customer classification management, characteristic of power supply package design to develop sales channels. Through the configuration of distributed energy, downstream terminal electrical equipment construction and supply gas, heat, cold and other forms of energy, to provide a one-stop solution for users of various energy supply, enhance the comprehensive competitiveness. In addition, by providing electricity for the user agent, can use information, electricity buyback, comprehensive energy consulting services, comprehensive low carbon energy solutions, contract energy management and other value-added services to achieve the innovation of the sale of electricity companies operating mode.

\section{Acknowledgements}

This research is supported by "the Fundamental Research Funds for the Central Universities" (2014MS146)

\section{References}

[1] Zhou Zhiqiang. Strengthen direct purchase of electric market, grab the placing of electricity market opportunities -- Based on Market Research in the new electric power system reform [J]. Sichuan hydropower, 2015,06:192-196.

[2] Li Ang, Xia Qing.The marketing mode of electricity market and the new electricity price system under the new situation [J].Power system protection and control under the new situation, 2016,05:10-16.

[3] Zhang Ningning. The sale of electricity companies how to build the system reform of electric power marketing system China [J]. Energy, 2016,04:44-47.

[4] Chen Zhen, Cui Feng, Xia Xu Dong, Hu Ruicong, Zang Zhen, Ma Huiqing. Electric power system reform and its marketing mode. [J]. China Institute of technology, 2016,02:24-28.

[5] Ma Li, Zhang Xiaoxuan, Wei Zhe, Xue Song, Yang Su. The experience and Revelation of the sale of electricity market in France, [J]. Southern Power Grid technology, 2015,08:9-12.

[6] Pan Jun. Marketing changes in the sale of electricity side of the new situation [J].Scientific consulting (Science and Technology Management), 2016,10:70. 